Daccache A, Weatherhead EK, Lamaddalena N. Climate change and the performance of pressurized irrigation water distribution networks under M editerranean conditions: Impacts and adaptations. Outlook on Agriculture, Vol.39(4), 2010, pages 277-283. (C) 2010 IP Publishing Ltd. Reproduced by permission. (http:// www.ippublishing.com).

\title{
Climate change and the performance of pressurized irrigation water distribution networks under Mediterranean conditions
}

\section{Impacts and adaptations}

\author{
Andre Daccache, Keith Weatherhead and \\ Nicola Lamaddalena
}

\begin{abstract}
Numerous previous studies have modelled the impact of climate change on crop water requirements and hence future water resource needs for irrigated agriculture. Fewer have considered the impacts on the performance of irrigation systems and the required engineering and managerial adaptations. This study considers the impacts and adaptations for a typical pressurized pipe irrigation system. The dry years of the baseline period (1970-90) in the southern part of Italy are expected to become the average or even wet year by the 2050s, according to HadCM3 projections. Under these conditions, the large water distribution systems designed to satisfy the baseline dry years will fail unless appropriate engineering or managerial adaptations are made. The resilience of District 8 of the Sinistra Ofanto to the possible future increase in irrigation demand has been assessed. A stochastic weather generator was used to generate future weather under the IPCC A1 and B1 emissions scenarios, taking into consideration the outputs of the HadCM3 model. A daily water balance model was used to quantify the actual and future peak water demand of the district. The reliability of each hydrant under baseline and future demand was calculated using a stochastic hydraulic model and the failure zones identified. Under the current design, the system can tolerate a peak demand discharge up to 1,500 l.s $\mathrm{s}^{-1}$, which is below the 2050 s $^{\prime}$ average $\left(1,720\right.$ l.s $\left.\mathrm{s}^{-1}\right)$. Above that value, the performance of the system will fall drastically as the number of unreliable hydrants will increase. In the future, assuming the same cropping pattern, the threshold discharge $\left(1,500\right.$ l. $\left.\mathrm{s}^{-1}\right)$ will be exceeded $80 \%$ of the time and, as an average, $20 \%$ of the system's hydrants will be failing during the peak demand periods. The adaptation options available to farmers and system managers in response to the increasing demand are discussed.
\end{abstract}

Keywords: irrigation demand; on-demand irrigation; performance analysis; resilience; Italy 
Numerous previous studies have modelled the impact of climate change on crop water requirements and hence future water resource needs for irrigated agriculture (for example, Rodríguez Díaz et al, 2007; De Silva et al, 2007; Chung et al, 2010). Fewer have considered the impacts on the performance of the irrigation distribution system itself and the required adaptations in engineering design and management. Daccache and Lamaddalena (2010) found that the pipe cost of a large water distribution system (District 4 of the Sinistra Ofanto scheme) would increase by $20-27 \%$ if designed according to the future irrigation demand. Pérez Urrestarazu et al (2010) concluded that the pumping capacity of the Fuente Palmera district (Spain) required for future demands would be difficult to satisfy. This study considers the impacts and potential adaptations for a typical pressurized pipe irrigation system taking District 8 of the Sinistra Ofanto scheme (southern Italy) as a case study.

Irrigation infrastructure such as reservoirs and water distribution systems has played an important role in improving the agricultural productivity in arid and semiarid regions and in benefiting the socioeconomic development of rural areas. Irrigated lands have expanded and new crops have been cultivated, while the yields and quality of traditional crops have improved. Compared with open channels, pressurized water distribution networks have many advantages, especially under arid and semi-arid conditions such as those in the south of Italy. These systems greatly reduce the water losses by evaporation and percolation during transportation. They help avoid uncontrolled water withdrawal. They can provide an easily metered, pressurized water service to each hydrant, and consequently are able to support a water pricing system based on the volume of water consumed by each user (Lamaddalena and Sagardoy, 2000).

In contrast to rotational supply, on-demand delivery schedules allow farmers to access water whenever and as often as required, depending on water availability. Ondemand supply is highly desired by farmers since it allows them greater flexibility in managing their businesses. Apart from the high capital cost, the main operational problem of these systems is pressure fluctuation in the pipes, caused by continual changes in the number and locations of the opened hydrants. A fluctuation at the upstream end of an on-farm network (that is, at the hydrant) can affect the uniformity and the amount of water applied in both drip and sprinkler systems (Daccache et al, 2010a, 2010b). Pressurized irrigation networks are normally designed and sized to operate at a given minimum hydrant pressure. For an ondemand system, the total discharge is calculated for a maximum number of opened hydrants, based on statistical parameters. However, in the peak demand period, the discharge flowing in the network can exceed the design discharge, putting the operational performance of the system at risk. The peak demand discharge depends on the cropping pattern and farmers' irrigation practices, but also on the meteorological conditions. The climate of southern Italy is expected to become warmer and drier, according to climate change projections, and the peak water needed for a given cropping pattern will increase.

The aim of this research is to examine how resilient a

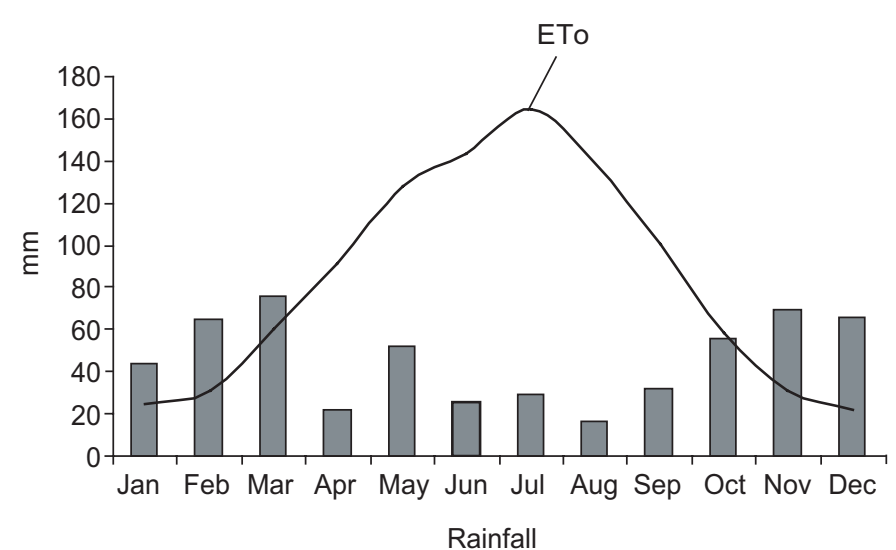

Figure 1. Mean monthly rainfall and reference evapotranspiration (ETo) for 1970-90 at the study site.

typical pressurized irrigation water distribution network is to such increases. Peak discharges were quantified under baseline and future climate conditions, initially assuming an unchanged cropping pattern. The reliability of each hydrant to deliver the appropriate pressure head for the on-farm network was then evaluated, and the resilience of the system to the increase in peak demand flow was analysed. Based on the results from this type of analysis, irrigation district managers can then develop engineering or managerial adaptation action plans to avoid, minimize or simply cope with future failures of these types of water distribution systems.

\section{Study site}

The Apulia region (southern Italy) has a typical semi-arid Mediterranean climate characterized by hot, dry summers and mild, wet winters. The largest water deficit (evapotranspiration-rain) occurs during the summer months (Figure 1) and coincides with the maximum canopy development of most of the crops grown in the area. The winter flow of the Ofanto River is diverted and stored in the Capaciotti Dam reservoir, which has a maximum storage capacity of 48 million $\mathrm{m}^{3}$ intended to irrigate the lowlands of the Sinistra Ofanto scheme (Figure 2). The water volume accumulated in the reservoir depends greatly on the dryness or wetness of each year. From the Capaciotti Dam, water is then conveyed to five accumulation and compensation reservoirs that serve seven irrigation districts (Figure 2). From the reservoirs right down to the on-farm systems, water is distributed by means of pipes and pressurized only by gravity.

District 8 was chosen for the study. The reservoir supplying District 8 has a storage capacity of $26,000 \mathrm{~m}^{3}$, with maximum and minimum water levels of $102 \mathrm{~m}$ and $98 \mathrm{~m}$ above sea level (asl) respectively. The irrigation district is designed to satisfy 2,856 ha of irrigated lands mainly occupied by grapes (54\%), olive trees (28\%), fruit trees $(10 \%)$, tomatoes and small vegetables. Being dominated by deep-rooted and permanent crops, the cropping pattern of the district shows a limited interannual change, while the actual area irrigated and the volume applied each year are dependent on both the 


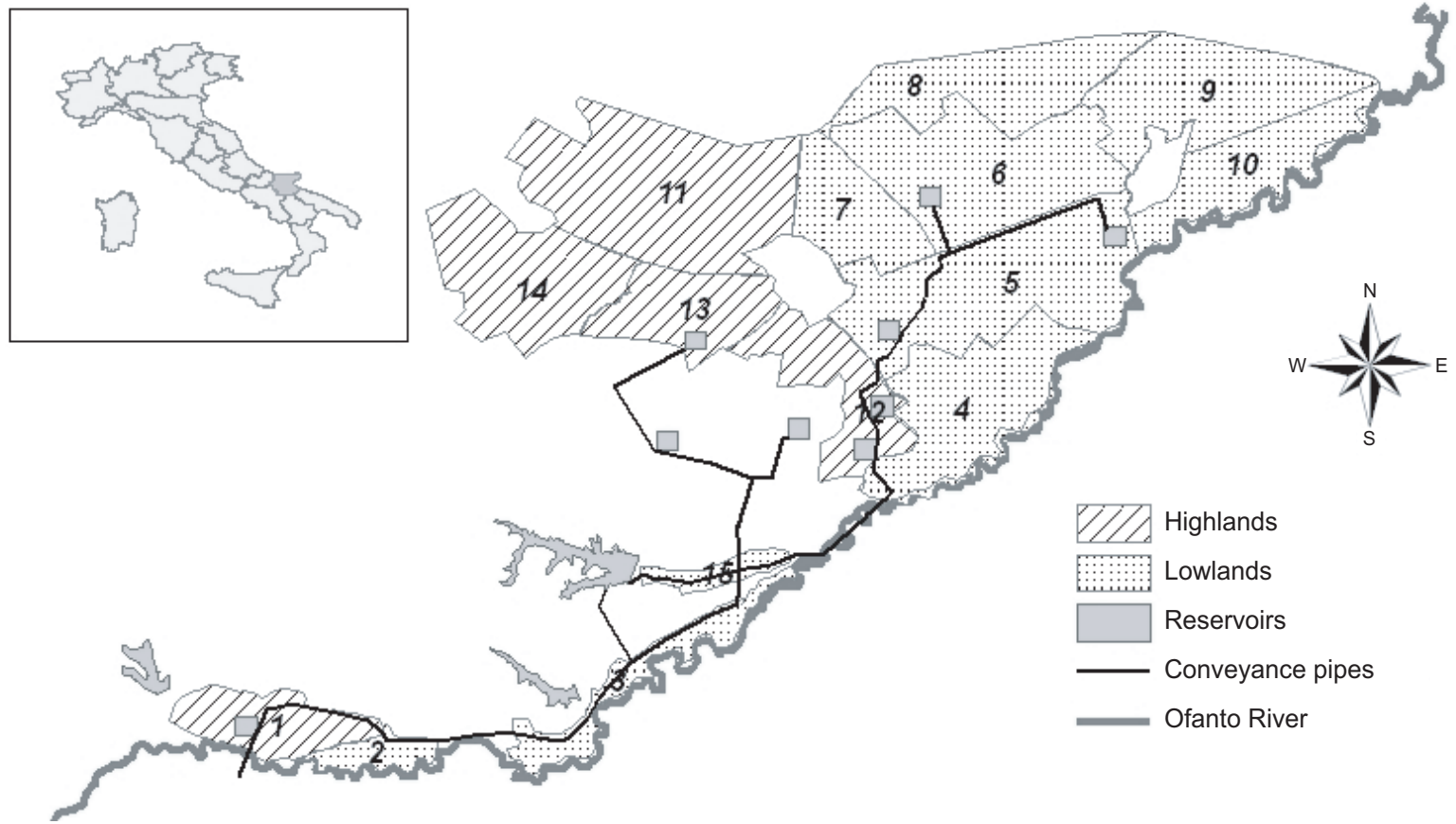

Figure 2. Layout of the Sinistra Ofanto irrigation scheme, showing the Capaciotti Dam, accumulation reservoirs and irrigation districts of the low- and highlands.

climatic conditions and the volume of water stored in the upstream reservoir. Drip irrigation is the only application method used in the district. Despite their high capital cost, drip systems fit well into these semi-arid conditions where water is scarce, labour is expensive and frequent irrigation is needed.

\section{Material and methods}

In summary, a weather generator was calibrated for the observed baseline weather (1970-90) and used with the outputs of a global climate model (GCM) to generate a future synthetic weather dataset for two emissions scenarios (Figure 3). The historical (1970-90) and future (2050s) irrigation needs of the main crops grown in the district were then computed using a daily water balance model. For the present cropping pattern, the historical and future peak water demands at the upstream end of the distribution system were identified. These were then used in a stochastic hydraulic simulation model to evaluate the level of failure or success of the system in delivering the required pressure heads at the hydrant level under a range of open hydrant permutations. Hence for every peak water demand, the reliability of each hydrant in delivering the desired pressure head was identified.

\section{Generation of future weather}

The nearest weather station to the study site (lat: $41^{\circ} 13^{\prime} \mathrm{N}$, long: $16^{\circ} 4^{\prime} \mathrm{E}$ and alt: $140 \mathrm{~m}$ asl) had only temperature and rainfall data available from 1970 to 1987, but a complete climate dataset from 1987 onwards. The PenmanMonteith method is recommended as the international standard to calculate reference evapotranspiration (ETo) in both humid and arid environments (Smith, 2000), but requires a complete climate dataset, while the empirical formula of Hargreaves-Samani (1982) needs only minimum and maximum temperatures. To overcome the problem of missing data, the Penman-Monteith and Hargreaves-Samani methods were both used to calculate

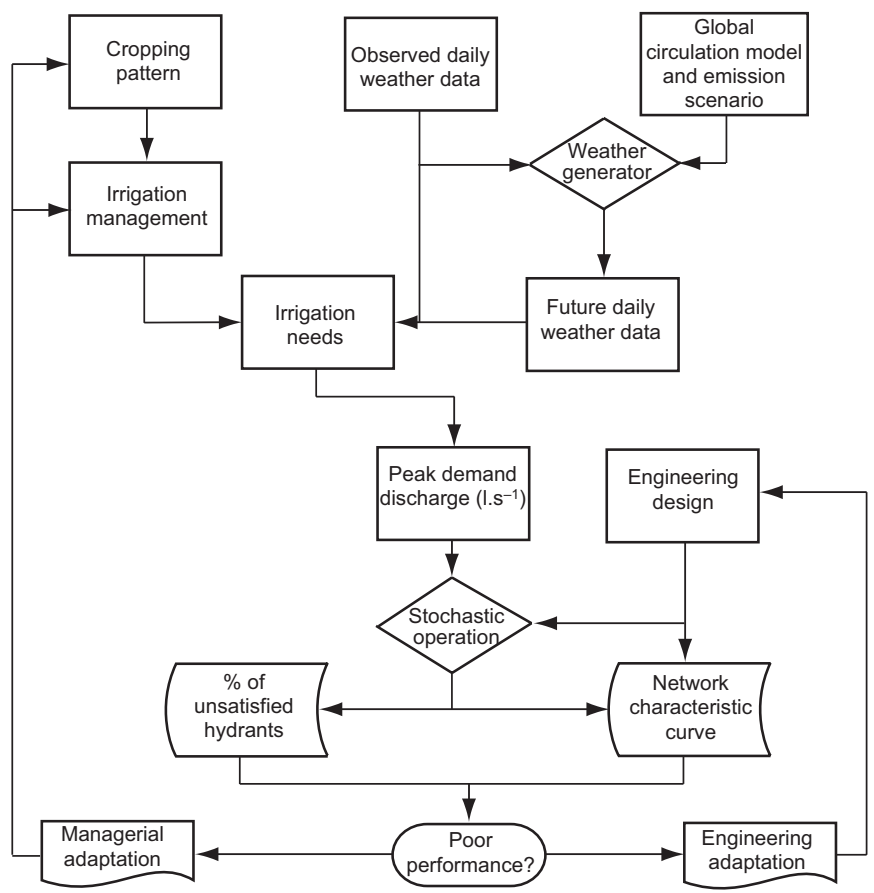

Figure 3. Summary of the methodology used in the study. 
the daily ETo for the latter period (1988-2009). The correlation between ETo values obtained with the two methods was then used to adjust the ETo values of Hargreaves-Samani (1982) for the historical baseline period (1970-90).

A LARS-WG stochastic weather generator (Semenov and Barrow, 1997) was used to produce daily weather from GCM outputs at a single site. LARS-WG utilizes semi-empirical distributions for the lengths of wet and dry day series, daily precipitation and daily solar radiation (Racsko et al, 1991). The observed weather data are analysed to determine their statistical characteristics. These are used to generate synthetic weather data having the same statistical characteristics as the original observed data, but differing on a day-to-day basis. Synthetic data corresponding to a particular future climate change scenario are generated by applying global climate modelderived changes in precipitation, temperature and solar radiation to the LARS-WG parameter files.

The HadCM3 (Hadley Centre Coupled Model, version 3) was chosen for this study since it was one of the major models used in the Intergovernmental Panel on Climate Change (IPCC) Third Assessment Report. HadCM3 is a coupled atmosphere-ocean general circulation model developed at the Hadley Centre and has a spatial resolution of $2.5^{\circ} \times 3.75^{\circ}$. The emissions scenarios used are those developed by the IPCC (Nakicenovic et al, 2000) in which each scenario combines two sets of divergent tendencies: one set varying between strong economic values and strong environmental values, the other set varying between increasing globalization and increasing regionalization (IPCC-TGCIA, 1999). In this work, the A1 and B1 emissions scenarios were used; both are characterized by a rapid economic growth and a global population that reaches nine billion in 2050 and then gradually declines. The A1 scenario characterizes a future with energy technology balanced between fossil and nonfossil fuel, whilst the B1 scenario reflects global efforts to control greenhouse gas (GHG) emissions through the introduction of clean and resource-efficient technologies.

\section{Irrigation demand}

The irrigation demand for the main crops grown in the irrigation district was computed using the WaSim daily soil water balance model (Graves et al, 2002). The local irrigation practices on olive trees and vineyards, such as scheduling to improve yield quality rather than quantity, were taken into account. Numerous researchers (Ciollaro et al, 1993; Di Chio, 1997; and Khadra, 2004) have previously noticed that water consumption in the Sinistra Ofanto scheme is lower than required for fully meeting water stress, confirming that deficit irrigation is widely practised in that area. The monthly water demand required to satisfy the irrigation needs of the present cropping pattern was identified by the WaSim model for each year (baseline and future). This provided the peak upstream discharge for the hydraulic modelling, expressed in $1 . \mathrm{s}^{-1}$.

\section{Hydraulic modelling}

As the volume of water flowing in the pipe system increases, the friction losses increase, reducing the pressure head at the hydrants. In networks operating on demand, the friction losses are distributed in the system according to the number and location of the opened hydrants. This will cause a certain level of pressure fluctuation at each hydrant that can cause a system failure under peak demand (Lamaddalena et al, 2007). The COPAM model (Lamaddalena and Sagardoy, 2000) is a stochastical simulation model that generates a large number of random configurations of hydrants simultaneously open to simulate the range of possible operating conditions of the on-demand system at a given upstream discharge. For each configuration, the pipeline system performance is resolved based on the continuity principle at junctions and standard friction formulae, and the amount of pressure at the hydrants is obtained. A hydrant is considered satisfied only when the pressure is higher than the minimum pressure $\left(H_{\text {min }}\right)$ required for appropriate functioning of the on-farm network and failure.

The hydrant reliability described by Hashimoto et al (1982) was used in this study to describe the failure probability of each hydrant in the system. The reliability indicator (Lamaddalena and Sagardoy, 2000) is summarized as:

$$
\alpha_{j}=\frac{\sum_{r=1}^{C} I h_{j, r} I p_{j, r}}{\sum_{r=1}^{C} I h_{j, r}}
$$

where:

$\alpha_{j} \quad=$ reliability of the hydrant, $j$

$I h_{j, r}=1$ if the hydrant, $j$, is open in the configuration, $r$

$I h_{j, r}^{j, r}=0$ if the hydrant, $j$, is closed in the configuration, $r$

$I p_{j, r}=1$ if the pressure head at the hydrant, $j$, open in the configuration, $r$, is higher than the minimum pressure head $\left(H_{\min }\right)$

$I p_{j, r}=0$ if the pressure head at the hydrant, $j$, open in the configuration, $r$, is lower than the minimum pressure head $\left(H_{\text {min }}\right)$

$\mathrm{C}=$ total number of configurations generated

For each configuration, the pressure head $(m)$ at each operating hydrant is calculated and consequently the indexes $I h_{j, r}$ and $I p_{j, r}$ are obtained. Once the satisfaction probability $\alpha_{j}$ for each hydrant $j$ in the system is calculated, the critical hydrants are then identified and mapped to highlight the failure zones in the district.

\section{Results and discussion}

\section{Irrigation requirement}

The average historical (1970-90) and projected future irrigation needs (2050s) for the study site for the IPCC A1 and B1 emissions scenarios are presented in Figure 4. The error bars represent the range of variation in irrigation requirements caused by the annual change in climatic conditions. In other words, these bars reflect the range of dryness and wetness during that specific time period. The future irrigation requirements for the major crops grown in the district noticeably increase, with only minor differences between the two emissions scenarios. For tomatoes and fruit trees, the future projections show that the wettest years in the 2050s will be drier than the driest 


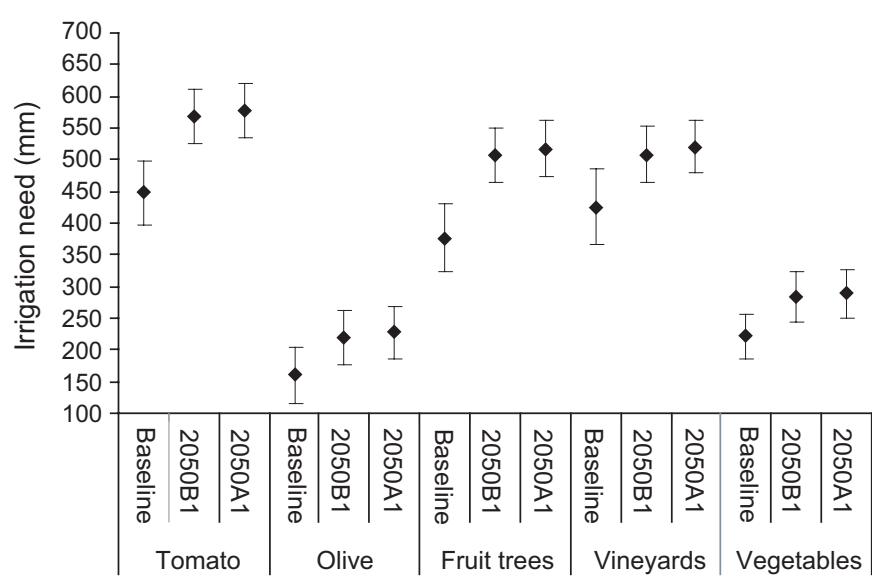

Figure 4. Baseline and future irrigation needs of the major crops grown in District 8 for the baseline period (1970-90) and the 2050s, with B1 (2050_B1) and A1 (2050_A1) emissions scenarios. Error bars represent the inter-annual variation in irrigation need in response to the weather conditions.

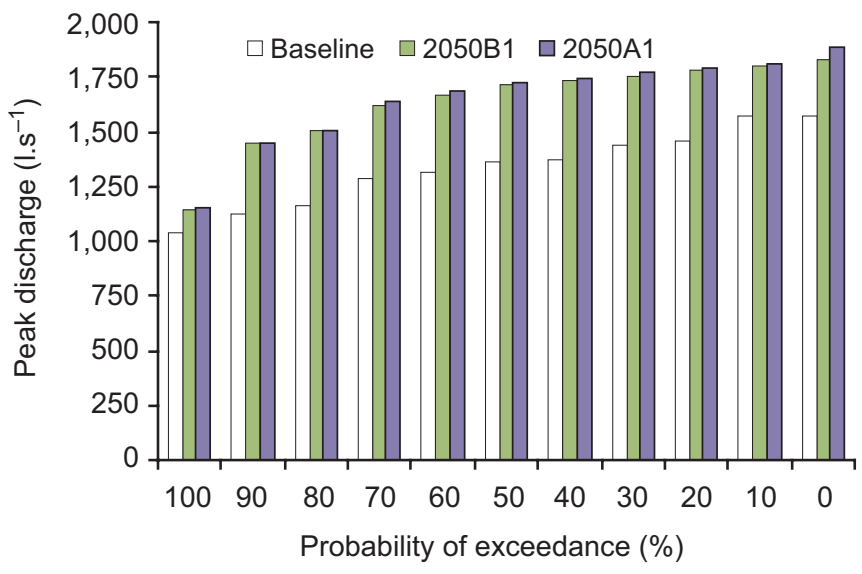

Figure 5. Probability of exceedance for District 8 peak water demand $\left(1 . \mathrm{s}^{-1}\right)$ for the baseline period (1970-90) and the 2050s under B1 (2050_B1) and A1 (2050_A1) emissions scenarios.

year observed during the baseline period. For the other crops, the future wettest years will correspond to the average or even to the dry years of the baseline period. Climate change, according to these results, will seriously affect an agricultural sector that is already struggling to compete with other users in the region for scarce water resources.

Assuming the same irrigated cropping pattern, an increase in irrigation demand implies an increase in the volume of water flowing through the pipe system. The historical and future peak demand discharges were identified by the WaSim model for every year and expressed as a probability of exceedance (Figure 5). For the baseline, the peak water demand to satisfy the district's crops ranges between 1,000 1.s $\mathrm{s}^{-1}$ (1984) and $1,5751 . \mathrm{s}^{-1}$ (1981). In the 2050s, the peak discharge shows only a minor change between the two emission scenarios,

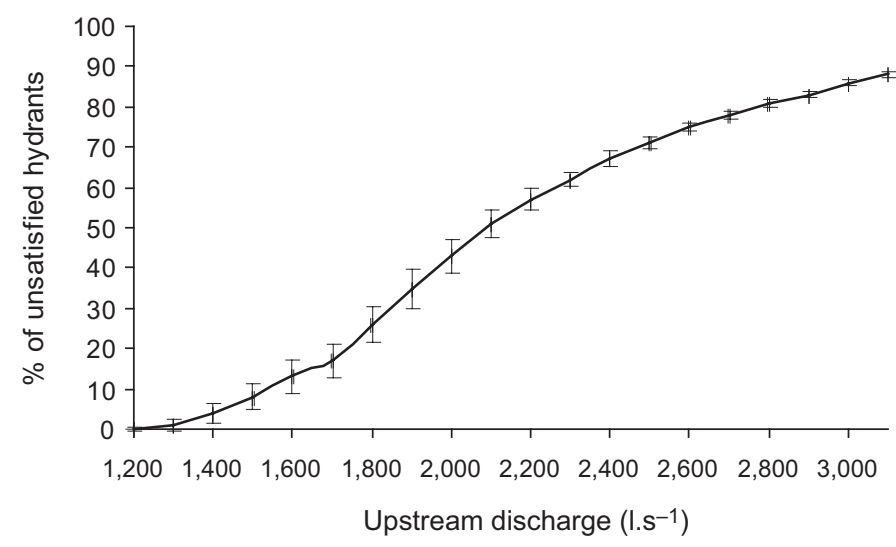

Figure 6. Percentage of unsatisfied hydrants $(\mathrm{H}<20 \mathrm{~m})$ with $80 \%$ occurrence probability at different upstream discharges. Error bars show the range of variation caused by the different configurations of opened hydrants.

and fluctuates, according to the dryness or wetness of the year, between $1,1501 . \mathrm{s}^{-1}$ and $1,880 \mathrm{l} \cdot \mathrm{s}^{-1}$. The highest peak water demand in the baseline period $\left(1,5751 . \mathrm{s}^{-1}\right)$ will be exceeded for $80 \%$ of the time in the 2050 s.

\section{System performance}

As previously mentioned, a hydrant is considered unsatisfied when its pressure head is lower than the minimum required (Hmin). Up to a discharge of 1,500 1. $\mathrm{s}^{-1}$ the system will perform adequately, as fewer than $10 \%$ of the system's hydrants have less than $20 \%$ probability to fail at peak demand period. The high cost of providing larger pipes justifies this small failure level in the system. As the peak demand discharge increases, the number of hydrants with pressure head lower than $20 \mathrm{~m}$ increases (Figure 6). At a discharge higher than 2,100 $1 . \mathrm{s}^{-1}$, a large fraction of the system might fail as the minimum pressure required would not be met in more than $50 \%$ of the systems' hydrants at peak demand.

To identify the zones where the hydrants are most susceptible to failure, the district was analysed at two different discharges $-1,3601 . \mathrm{s}^{-1}$ and 1,720 1.s $\mathrm{s}^{-1}$ corresponding to average peak demand for the baseline and 2050s periods respectively. Figure 7 shows the reliability of each hydrant at peak demand in an average year for the baseline and future (2050s). The number of hydrants that are less than $85 \%$ reliable is expected to increase from $14(2 \%)$ to $115(18 \%)$ and those that are highly reliable (>95\%) to drop from $569(90 \%)$ to 449 $(71 \%)$. The most affected hydrants are those located at the far downstream end of the system and those located on elevated lands for both periods.

\section{Adaptation and mitigation}

In response to this expected worsening of system performance, managers and farmers will need to adapt now or in the future through engineering and/or managerial changes. Engineering solutions are often considered first as they are the easiest for managers to control. Appropriate maintenance of the system could reduce the pipe leakage as well as friction losses from old 


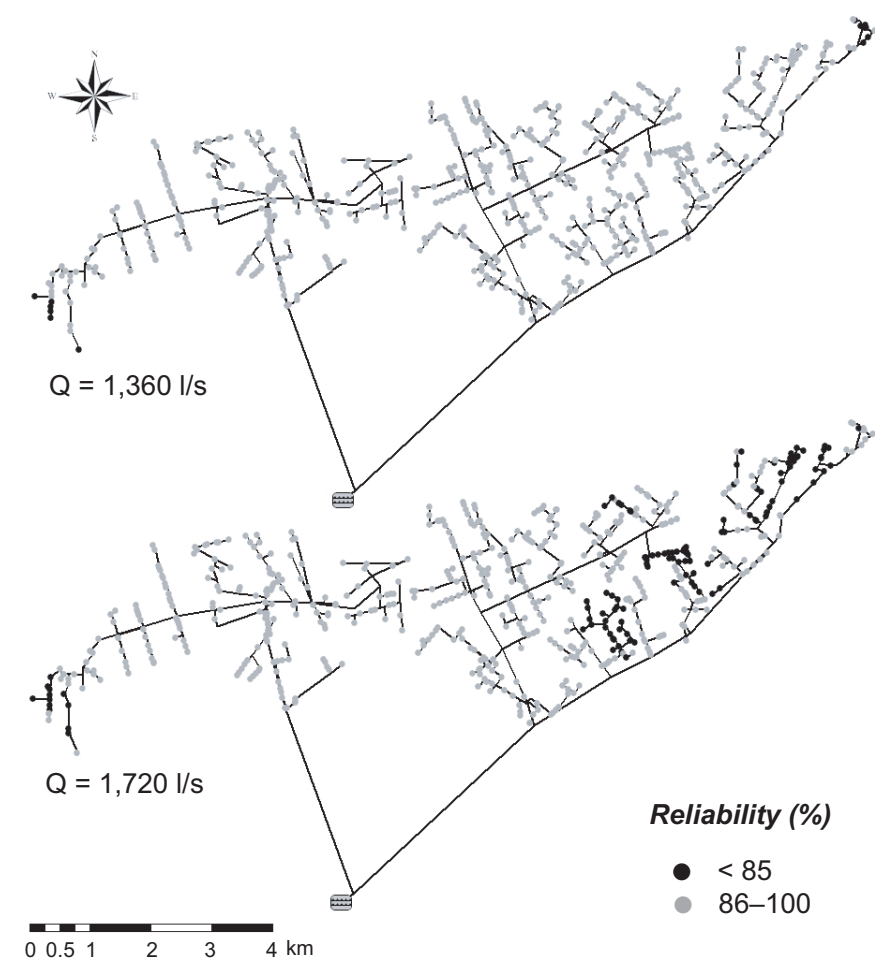

Figure 7. Reliability of District 8 hydrants at peak demand period during an average year for the baseline $\left(Q=1,3601 . \mathrm{s}^{-1}\right)$ and 2050s $\left(\mathrm{Q}=1,720\right.$ l.s $\left.{ }^{-1}\right)$ periods.

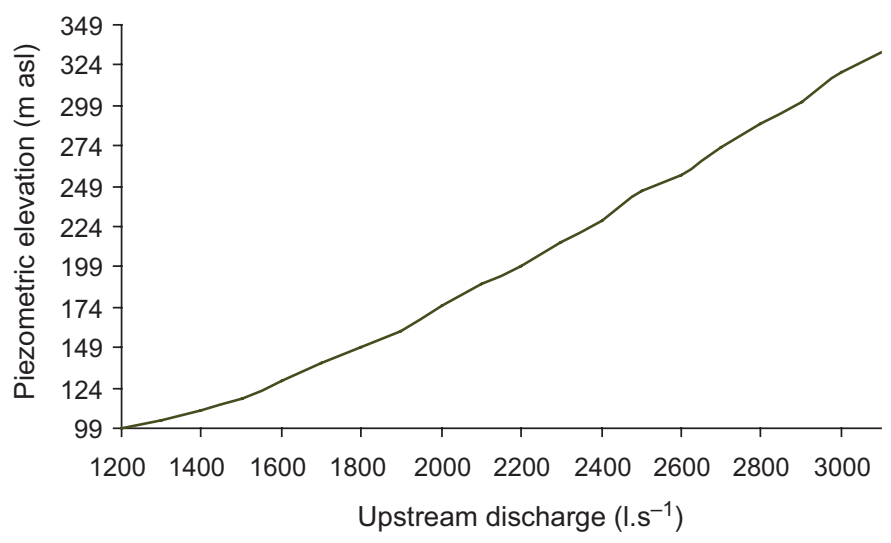

Figure 8. The characteristic curve of District 8 showing the minimum piezometric head ( $\mathrm{m}$ asl) required for different upstream discharges to achieve satisfactory hydrant pressures.

rough pipes. Increasing the pipe diameters to reduce friction losses once problems arise would be an expensive solution, though judicious dualling of critical pipelines can be effective. Using larger pipes at the design stage would usually be cheaper, but implies a significant extra cost well before the climate change effects become serious, and indeed while the impacts may still be uncertain or even disputed. More simply, at a later stage and as needed, the upstream piezometric head could be increased to overcome the increased friction losses in the pipe system. The characteristic curve of District 8 (Figure 8) shows the upstream piezometric head required at each peak demand discharge to satisfy all the hydrants at least $80 \%$ of the time. A pump at the intake could therefore be used to raise the piezometric head in response to water demand increases. Alternatively, smaller booster pumps could be used at critical hydrants or failure zones when required. However, both these options imply future pump and energy costs in what is currently a gravity-fed system.

Non-engineering-based solutions are more difficult to implement, and less efficient if not well managed, but less capital-intensive. The district managers could face the reduction in performance of these systems by reducing water consumption. Efficient use of water at the farm level by applying the minimum water in the right place at the right time must be a priority. This could be obtained through more efficient on-farm irrigation systems and appropriate irrigation scheduling. District managers usually do not have the power to intervene directly in farmer operations, but water saving could be encouraged by appropriate water pricing based on water consumption, extension services (technical training, meteorological services) and allocation of limited water volumes to each user. The use of low-energy precise application (LEPA) irrigation systems is also an option for hydrants subject to high risk of pressure failure. Managers could also restrict water use with electronic 'credit card' devices known as AquaCards limiting the operation of the hydrants with high failure risk at peak demand periods, and then re-activating them during off-peak periods (that is, at night). This latter option could reduce the burden of night-time irrigation if coupled with modern automated irrigation systems.

Sectoring of the system at peak demand periods has been used elsewhere to reduce the energy consumption and the risk of system failure. This option modifies the delivery schedule from an on-demand to a rotational operation, and thus reduces the operational freedom of the farmers. This practice does not necessarily achieve water saving and in certain conditions it can lead to increased demand and over-irrigation (Lamaddalena et al, 1995). This latter issue, combined with the fact that opened hydrants of a given sector are usually concentrated in the same network branch, means that the friction losses caused by the concentrated water volume flowing in that branch may aggravate the performance of the system. Finally, the cultivation of drought-tolerant varieties or the adoption of new water-saving techniques such as partial root drying, subsurface irrigation, deficit irrigation and mulching are potential farmer adaptations.

\section{Conclusions}

Future climate projections for Mediterranean Italy show a noticeable increase in summer evapotranspiration and hence in crop irrigation requirements. Consequently, farmers are expected to increase their demands on water, increasing the load for on-demand water distribution systems. During peak demand periods, the discharge flowing in the system may exceed the design discharge of the system, causing insufficient pressure head at the hydrant level, which can adversely affect the performance of the on-farm irrigation system. As a case study, District 
8 performs well under current (baseline) conditions and can satisfy more than $90 \%$ of its hydrants up to a peak water demand of 1,500 1.s $\mathrm{s}^{-1}$. However, above this value, the number of failing hydrants could increase drastically and the performance of the entire system might seriously deteriorate. In the future, assuming the same cropping pattern, the threshold discharge $\left(1,5001 . \mathrm{s}^{-1}\right)$ would be exceeded $80 \%$ of the time during the peak demand periods. There is a range of potential engineering and managerial adaptation options available to district managers, though all have cost and/or convenience drawbacks.

\section{References}

Chung, S., Rodríguez-Díaz, J. A., Weatherhead, E. K., and Knox, J. W. (2010), 'Climate change impacts on water for irrigating paddy rice in South Korea', Irrigation and Drainage, doi:10.1002/ ird.559.

Ciollaro, G., Lamaddalena, N., and Altieri, S. (1993), 'Analisi comparativa fra consume idrici stimati e misurati in un comprensorio irriguo dell'Italia meridionale', Rivista di Ingegneria Agraria, Vol 4, pp 234-243.

Daccache, A., and Lamaddalena, N. (2010), 'Climate change impacts on pressurised irrigation systems', Proceedings of the Institution of Civil Engineers: Engineering Sustainability, Vol 163, No 2, pp 97-105.

Daccache, A., Lamaddalena, N., and Fratino, U. (2010a), 'Assessing pressure changes in an on-demand water distribution system on drip irrigation performance - case study in Italy', Journal of Irrigation and Drainage Engineering, Vol 136, No 4, pp 261-270.

Daccache, A., Lamaddalena, N,. and Fratino, U. (2010b), ‘Ondemand pressurized water distribution system impacts on sprinkler network design and performance', Irrigation Science, Vol 28, No 4, pp 331-339.

De Silva, C. S., Weatherhead, E. K., Knox, J. W., and RodriguezDiaz, J. A. (2007), 'Predicting the impacts of climate change - a case study of paddy irrigation water requirements in Sri Lanka', Agricultural Water Management, Vol 93, No 1-2, pp 1929.

Di Chio, F. (1997), 'Fabbisogni irrigui delle colture, stimati e misurati, in un distretto irriguo in Sinistra Ofanto', Tesi di Laurea in Agronomia generale ed idraulica agrarian, Università degli studi di Bari, Facoltà di Agraria, Bari.

Graves, A. R., Hess, T., Matthews, R. B., Stephens, W., and Mason, T. (2002), 'Crop simulation models as tools in computer laboratory and classroom-based education', Journal of Natural Resources and Life Sciences Education, Vol 31, pp 48-54.
Hargreaves, G. H., and Samani, Z. A. (1982), 'Estimating potential evapotranspiration, tech. note', ASCE Journal of Irrigation and Drainage Engineering, Vol 108, No 3, pp 225-230.

Hashimoto, T., Stedinger, J. R., and Loukos, D. P. (1982), 'Reliability, resiliency and vulnerability criteria for planning water resources system performance evaluation', Water Resources Research, Vol 18, No 1, pp 14-20.

IPCC-TGCIA (1999), Guidelines on the Use of Scenario Data for Climate Impact and Adaptation Assessment, Version 1, prepared by Carter T. R., Hulme, M., and Lal, M., Intergovernmental Panel on Climate Change, Task Group on Scenarios for Climate Impact Assessment, Switzerland.

Khadra, R. (2004), 'Development of an integrated tool for the analysis of irrigation system under water scarcity conditions', PhD thesis, University of Bari, Italy.

Lamaddalena, N., Ciollaro, G., and Pereira, L. S. (1995), 'Effects of changing irrigation delivery schedules during periods of limited water availability of water', Journal of Agricultural Engineering Research, Vol 61, pp 261-266.

Lamaddalena, N., Fratino U., and Daccache, A. (2007), ‘On-farm sprinkler irrigation performance as affected by the distribution system', Biosystems Engineering, Vol 96, No 1, pp 99-109.

Lamaddalena, N., and Sagardoy, J. A. (2000), Performance Analysis of On-Demand Pressurized Irrigation Systems, FAO Irrigation and Drainage Paper No 59, FAO, Rome.

Nakicenovic, N., Alcamo, J., Davis, G., de Vries, B., Fenhann, J., Gaffin, S., Gregory, K., Grübler, A., Jung, T. Y., Kram, T., La Rovere, E. L., Michaelis, L., Mori, S., Morita, T., Pepper, W., Pitcher, H., Price, L., Raihi, K., Roehrl, A., Rogner, H., Sankovski, A., Schlesinger, M., Shukla, P., Smith, S., Swart, R., van Rooijen, S., Victor, N., and Dadi, Z. (2000), IPCC Special Report on Emissions Scenarios, Cambridge University Press, Cambridge.

Pérez Urrestarazu, L., Smout, I. K., Rodríguez Díaz, J. A., and Carrillo Cobo, M. T. (2010), 'Irrigation distribution networks' vulnerability to climate change', Journal of Irrigation and Drainage Engineering, Vol 136, No 7, pp 486-493.

Racsko, P., Szeidl, L., and Semenov, M. (1991), 'A serial approach to local stochastic weather models', Ecological Modelling, Vol 57, pp 27-41.

Rodríguez Díaz, J. A., Weatherhead, E. K., Knox, J. W., and Camacho, E. (2007), 'Climate change impacts on irrigation water requirements in the Guadalquivir river basin in Spain', Regional Environmental Change, Vol 7, No 3, pp 149-159.

Semenov, M. A., and Barrow, E. M. (1997), 'Use of a stochastic weather generator in the development of climate change scenarios', Climatic Change, Vol 35, pp 397-414.

Smith, M. (2000), 'The application of climatic data for planning and management of sustainable rain-fed and irrigated crop production', Agricultural and Forest Meteorology, Vol 103, pp 99108 